\title{
Sediment grain size and hydrodynamics in Mediterranean coastal lagoons: Integrated classification of abiotic parameters
}

\author{
Emanuela Molinaroli ${ }^{1, *}$, Alessandro Sarretta $^{2}$, Christian Ferrarin $^{3,4}$, \\ Emanuele Masiero $^{5}$, Antonietta Specchiulli ${ }^{6}$ and Stefano Guerzoni ${ }^{3}$ \\ ${ }^{1}$ Università Ca' Foscari Venezia, Dipartimento di Scienze Ambientali Informatica \\ e Statistica, Dorsoduro 2137, 30123 Venezia, Italy. \\ ${ }^{2}$ CNR-Consiglio Nazionale delle Ricerche, ISMAR - Istituto di Scienze Marine \\ in Bologna, via Gobetti 101, 40129 Bologna, Italy. \\ ${ }^{3}$ CNR-Consiglio Nazionale delle Ricerche, ISMAR - Istituto di Scienze Marine \\ in Venezia, Castello 2737/F, 30122 Venezia, Italy.

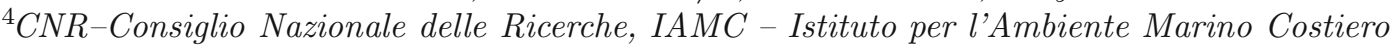 \\ in Oristano, 090782 Torregrande, Oristano, Italy. \\ ${ }^{5}$ Urban Planning, Via S. Martino 11-35030 Veggiano, Padova, Italy. \\ ${ }^{6}$ CNR-Consiglio Nazionale delle Ricerche, ISMAR Istituto di Scienze Marine \\ in Lesina, via Pola 4, 71010 Lesina (FG), Italy. \\ *Corresponding author.e-mail: molinaro@unive.it
}

Integrated classification maps were produced by combining sediment grain-size and hydrological data (water renewal time, WRT) from two Mediterranean lagoons, Lesina (LL) and Varano (LV), Italy. The geophysical characteristics of the two basins, derived from detailed bathymetric charts, are quite distinct: $\sim 30 \%$ of LL (mean depth $\sim 1 \mathrm{~m}$ ) but only $3 \%$ of LV (mean depth $\sim 3 \mathrm{~m}$ ) is shallower than $1 \mathrm{~m}$. The sediments of both lagoons are mainly composed of mud ( $~ 80 \%)$. A detailed multivariate analysis of grainsize data by EntropyMax classified the lagoon beds of LL and LV into five sedimentary facies. WRT data, computed by a hydrodynamic model, indicated different hydrological conditions in the two lagoons: LL showed a sharp west-east gradient, with a basin-wide average of $~ 190$ days, whilst LV showed a fairly uniform distribution and a higher basin-wide average ( $\sim 260$ days). The distribution of sedimentary facies and water renewal times were combined in a composite map representing the distribution of environmental patterns. The approach outlined in this study can be used to improve zonation schemes by providing a hydromorphological perspective on transitional and coastal environments.

\section{Introduction}

Hydrological or ecological data have been published for more than 50 coastal lagoons in the Mediterranean basin (Pérez-Ruzafa et al. 2011). Comparison of these data makes it possible to define the hydrological constraints on macrobenthic fauna (Barbone and Basset 2010) and to evaluate the extent to which their ecological characteristics (e.g., fish assemblage composition, zooplankton) depend on hydrographical or geomorphological features (Pérez-Ruzafa et al. 2007a; Ferrarin et al. 2008).

Keywords. Sediment grain-size; water renewal time; bathymetry; abiotic classification; EntropyMax; lagoon. 
Maps representing purely abiotic environmental patterns have been widely used with the assumption that biological trends can be inferred, although inferences are not always accurate or justified (Levin 2001; Lucieer and Lucieer 2009). Creation of habitat maps entails combining disparate data sets from biological, geophysical, and oceanographic sources (Brown et al. 2011). Pérez-Ruzafa et al. (2011) demonstrated that the variability of Mediterranean lagoon assemblages depends mainly on lagoon size, the rate of exchange with the open sea, differences in salinity with respect to the open sea, and the trophic status of the water column. Trophic status may be forced by several environmental parameters including grain-size, hydrodynamic conditions, and the presence of organic matter (Lourido et al. 2010; Malhadas et al. 2010). The approach based on the mapping of abiotic variables may provide useful representations of environmental patterns, allowing scientists and managers to understand the distribution of living and non-living resources on the sea bed (Anderson et al. 2008; Cogan et al. 2009; Shumchenia and King 2010; Stolt et al. 2011; Oakley et al. 2012).

The aim of this paper is to combine detailed grain-size data with hydrodynamic parameters (water renewal time, WRT) computed by means of a numerical approach in the Lagoons of Lesina (LL) and Varano (LV). Water renewal time data add to the characteristics of the lagoon bed a 'third dimension', based on overlying water conditions, which strongly influence benthic ecosystems (Ribbe et al. 2008; Brown et al. 2011).

The data were mapped and overlaid in order to produce, in tandem with bathymetric data, an integrated abiotic map. The abiotic zonation created in this study is flexible and can be adjusted to highlight areas where biological data may enable habitat prediction and a focus on environmental quality.

\section{Study sites}

The Lagoons of Lesina and Varano are located by the southern Adriatic Sea on the south-east coast of Italy $\left(41^{\circ} 88^{\prime} \mathrm{N}, 15^{\circ} 45^{\prime} \mathrm{E}\right)$ within the Gargano National Park, a protected area and tourist destination (figure 1). The tide in the open sea off the lagoons has a typical range of about $30 \mathrm{~cm}$. Tidal range in the lagoons is a few $\mathrm{cm}$, and the narrow connecting channels allow only limited exchange between the lagoons and the coastal system (Specchiulli et al. 2010). Wind-induced currents seem to be sufficient to cause resuspension and distribution of fine sediment particles within both basins (Crisciani 1994).
Given their surface area $\left(50-60 \mathrm{~km}^{2}\right)$, the lagoons are representative of large Mediterranean coastal lagoons (Basset et al. 2006; Tagliapietra and Volpi Ghirardini 2006; Pérez-Ruzafa et al. 2011; Duck and Figueiredo da Silva 2012).

The genesis of LL and LV is linked to littoral dynamics that led to the progressive growth of spits composed of clasts and other sediments drifting from the Fortore and Biferno river mouths located to the west. During the post-glacial age, these spits developed into a ridge of coastal dunes which closed off the bays on the landward side, forming the two lagoons. The lagoonal system probably developed after the Holocene climatic optimum, when the neotectonic phases were already concluded (De Pippo et al. 2001).

\subsection{The Lagoon of Lesina (LL)}

The surface area of LL is $51 \mathrm{~km}^{2}$, the catchment area is $\sim 400 \mathrm{~km}^{2}$ and the mean depth is $\sim 1 \mathrm{~m}$. The geological history and the morphological characteristics of the coastal zone suggest that the lagoon's development and evolution are linked to interactions between tecto-sedimentary, climatic and hydrodynamic factors during the late PleistoceneHolocene (De Pippo et al. 2001).

The lagoon's shape and depth have undergone changes due to constant sediment filling. Thin peat levels alternating with marine sandy-silty sediments suggest that marine and marshy stages alternated during the lagoonal system's evolution. Exchange with the Adriatic Sea occurs through two artificial channels, Acquarotta, located at the western end, and Schiapparo, at the eastern end of the lagoon. Overall, the lagoon is very shallow, the depth never exceeding $1.6 \mathrm{~m}$. North-northwesterly winds are very frequent in this area, especially during winter, increasing sea water input to the lagoon.

There are strong seasonal variations in salinity (from 10 to 28 psu) (Roselli et al. 2009). Furthermore, the western region of the lagoon generally exhibits higher salinity than the eastern region. This is due to the fact that the lagoon receives fresh water from small tributaries, mostly located in the eastern part of the basin, which drain the majority of the surface and subsurface water coming from the adjacent karstic promontory. Partially treated waste water from the lagoon's catchment area is also discharged into the lagoon. The economic value of LL derives mostly from commercial fishing and extensive aquaculture (De Pippo et al. 2001).

\subsection{The Lagoon of Varano (LV)}

LV is the largest brackish basin in southern Italy $\left(65 \mathrm{~km}^{2}\right)$ and one of the largest brackish systems 


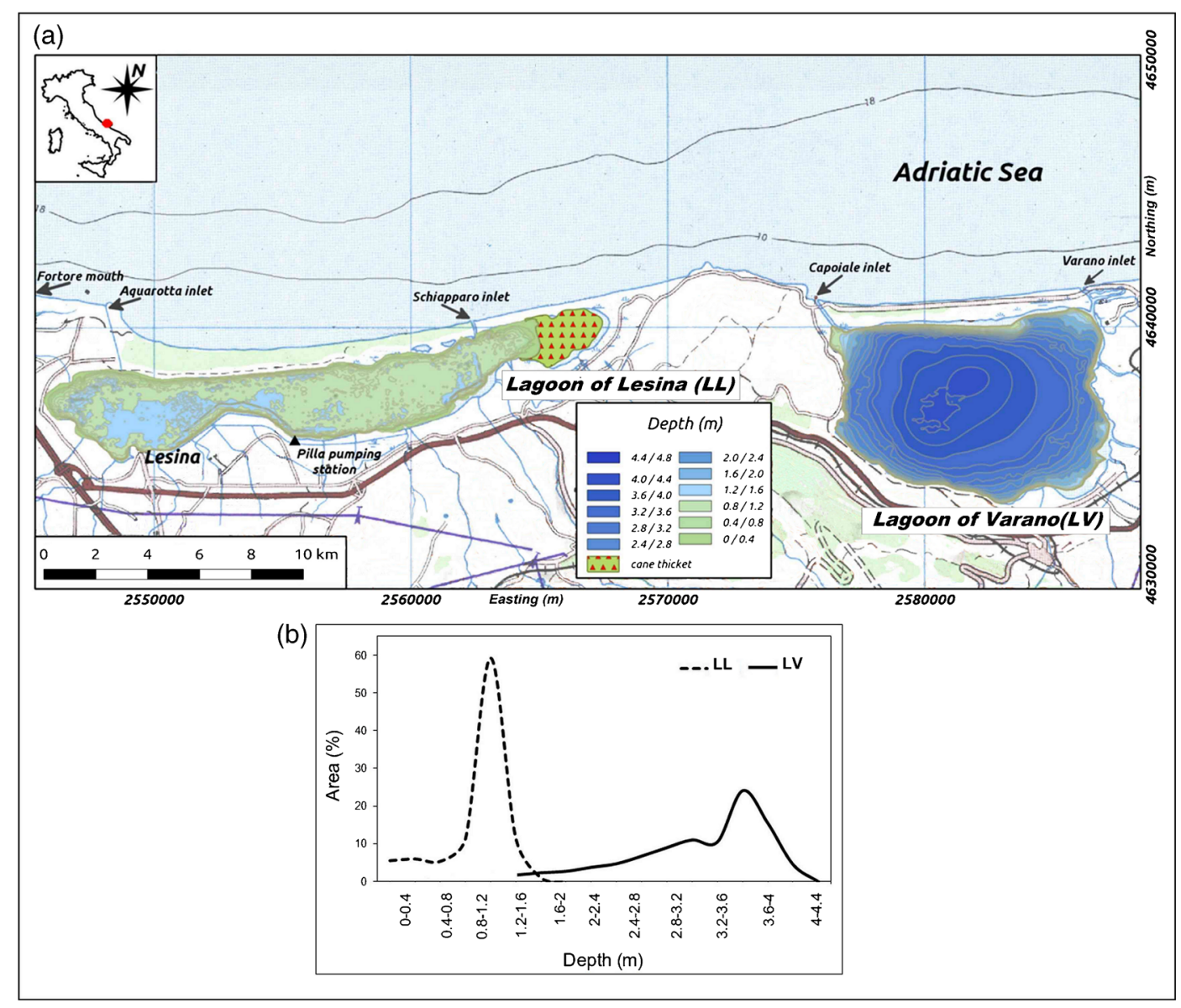

Figure 1. Map of Lesina and Varano lagoons with bathymetric maps. (a) Distribution of specific elevation categories in Lagoons of Lesina (dotted line) and Varano (solid line). (b) Projection datum is Roma 40 (Gauss-Boaga/East).

in the western Mediterranean. The catchment area is $\sim 300 \mathrm{~km}^{2}$ and the mean depth is $\sim 3 \mathrm{~m}$. Bosellini et al. (1999) argue that the depression that accommodates the LV was originally a Cretaceous submarine slide scar resulting from a large-scale platform collapse. Sea water exchange between LV and the Adriatic Sea occurs by means of two artificial channels, Foce Capoiale on the western side and Foce Varano on the eastern side of the lagoon. LV does not have morphological features such as intertidal marshes, intertidal mud flats, submerged mud flats, and navigation channels. The maximum depth of the lagoon $(>4 \mathrm{~m})$ is in the central-southern region. Salinity is relatively constant, ranging from 23 to $29 \mathrm{psu}$ (Caroppo 2000; Specchiulli et al. 2008). LV receives freshwater inputs rich in organic content from urban and agricultural run-off, fish-farming and livestock breeding (Spagnoli et al. 2002). Other freshwater inputs come from groundwater springs in the south-western sector of the lagoon and urban wastewater discharge in the south-eastern zone. Mussel cultivation (Mytilus galloprovincialis) is the most important economic activity carried out in the lagoon.

\section{Material and methods}

\subsection{Bathymetric datasets}

The data for LL and LV were collected during two survey campaigns in May-June 2001 by CONISMA-DiSGAM (2002a, b). A total of $280 \mathrm{~km}$ of acquisition profiles in LL and $200 \mathrm{~km}$ in LV were recorded. A PSA900 vertical incidence echosounder manufactured by Datasonics was used for the channels (depth $\sim 3 \mathrm{~m}$ ), and a single-beam echo-sounder (Datasonics PSA-916, $200 \mathrm{kHz}$ ) was used for shallow waters $(30 \mathrm{~cm}<$ depth $>3 \mathrm{~m})$. The depth soundings were positioned with an accuracy of $\pm 1 \mathrm{~m}$ using a Fugro 3200LR12 DGPS receiver. To increase the coverage obtained by each track, 3-4 echo-sounders were mounted on a bar. The echosounder and the GPS antenna were mounted on a flat-keel boat equipped with the instruments used during the survey. Where depth was $<30 \mathrm{~cm}$ (areas near the shoreline), data were collected by the traditional topographic method (stadia rods with GPS). The survey was performed on a grid with profiles at a distance of $100 \mathrm{~m}$. Tidal excursion in the lagoon was assumed 
to be zero (CoNISMa-DiSGAM 2002a, b). The projection datum is Roma 40 (Gauss-Boaga/East). The bathymetric data were interpolated and classified and are presented in the form of colour-shaded maps (figure 1).

\subsection{Sediment sampling and analysis (ternary methods)}

Three hundred samples in each lagoon were selected from sites sampled by CoNISMa-DiSGAM (2002a, b). Sampling locations were distributed uniformly throughout both lagoons: the distance between samples was $\sim 400 \mathrm{~m}$. Sediment samples ( $\sim 10 \mathrm{~cm}$ depth) were collected using a Van Veen grab. The samples were pre-treated with $\mathrm{H}_{2} \mathrm{O}_{2}$ (20 vol.\%) to eliminate organic material, washed with bi-distilled water to eliminate chlorides, and then oven-dried at $40^{\circ} \mathrm{C}$ for $12 \mathrm{~h}$. The samples were sieved for the $<2 \mathrm{~mm}$ fraction in order to eliminate clam shells and fragments. Grain size analyses of the sediments were performed by sedimentation balance and a SediGraph 5100 (Micromeritics ${ }^{\mathrm{TM}}$ ) particle analyser for the sand $(>63 \mu \mathrm{m})$ and mud $(<63 \mu \mathrm{m})$ fractions respectively. The mud samples were pre-treated with 6\%o Na-hexametaphosphate solution for $24 \mathrm{~h}$. Sediments were classified using a ternary diagram based on sand/mud ratios (Flemming 2000) (figure 2).

\subsection{EntropyMax analysis}

The grain-size fractions were subjected to EntropyMax analysis. The concept of entropy, in terms of particle size, can be demonstrated by considering a completely flat size distribution, where all particle mass occurs with the same frequency throughout the distribution. This is essentially a random distribution of matter throughout the size distribution, so that a size spectrum with this shape has maximum entropy. On the other hand, in a size distribution where all particle mass is found in only one interval there is no randomness of distribution and the entropy is at a minimum. EntropyMax (Stewart et al. 2009) is a Windows-based, Visual Basic 6 software tool that represents an updated and improved version of entropy (Woolfe and Michibayashi 1995). The software is designed to ensure optimal grouping, maximising the inequality between groups of samples and minimising the inequality within the groups, so that the distributions in each group have similar shapes, and the shapes of the distributions differ mainly between groups (Stewart et al. 2009). EntropyMax allows

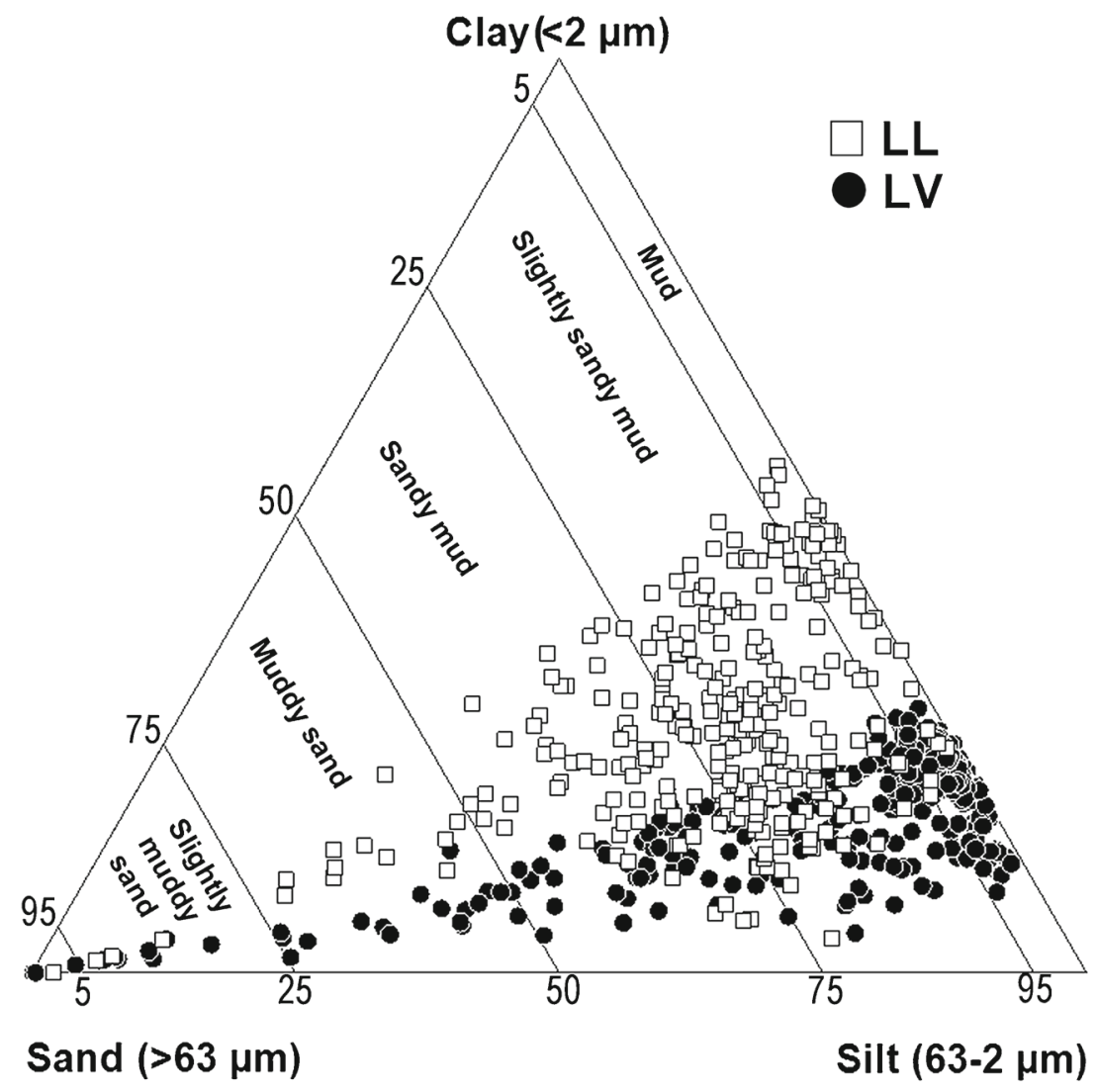

Figure 2. Ternary diagram of surficial LL and LV sediments based on sand/mud ratios. 
optimal classification of samples into self-similar groups (figures 3 and 4 ). The procedure optimises the classification of $N$ samples into $R$ groups by maximising inter-group and minimising intragroup entropy. The efficiency of this classification in terms of maximising inter-group inequality is given by the so-called $R s$ statistic, which is the percentage of the 'dataset' explained, while the optimum number of groups is indicated by the Chalinski-Harabasz $(\mathrm{C}-\mathrm{H})$ criterion (Stewart et al. 2009) (table 1).

\subsection{Hydrological parameters and description of the model}

In this study we applied a two-dimensional finite element shallow water model in order to describe the temporal and spatial variations of the hydrodynamic regimes of the two lagoons. The hydrodynamic model used in this study (SHYFEM, https://www.ismar.cnr.it/shyfem) has already been applied to LL (Ferrarin et al. 2014) and many coastal environments (Umgiesser et al. 2004; Ferrarin and Umgiesser 2005; Ferrarin et al. 2010; De Pascalis et al. 2012; Ferrarin et al. 2013a). For each basin, the numerical computation was carried out on a spatial domain representing the lagoon itself and a part of the Adriatic Sea shelf in front of it (figure 5). The finite element method allows for strict reproduction of the system's morphology and bathymetry. In addition, it is able to represent zones where hydrodynamic activity is greater, such as connecting channels. The numerical resolution of the finite element model is generally higher than the grab sample mesh,
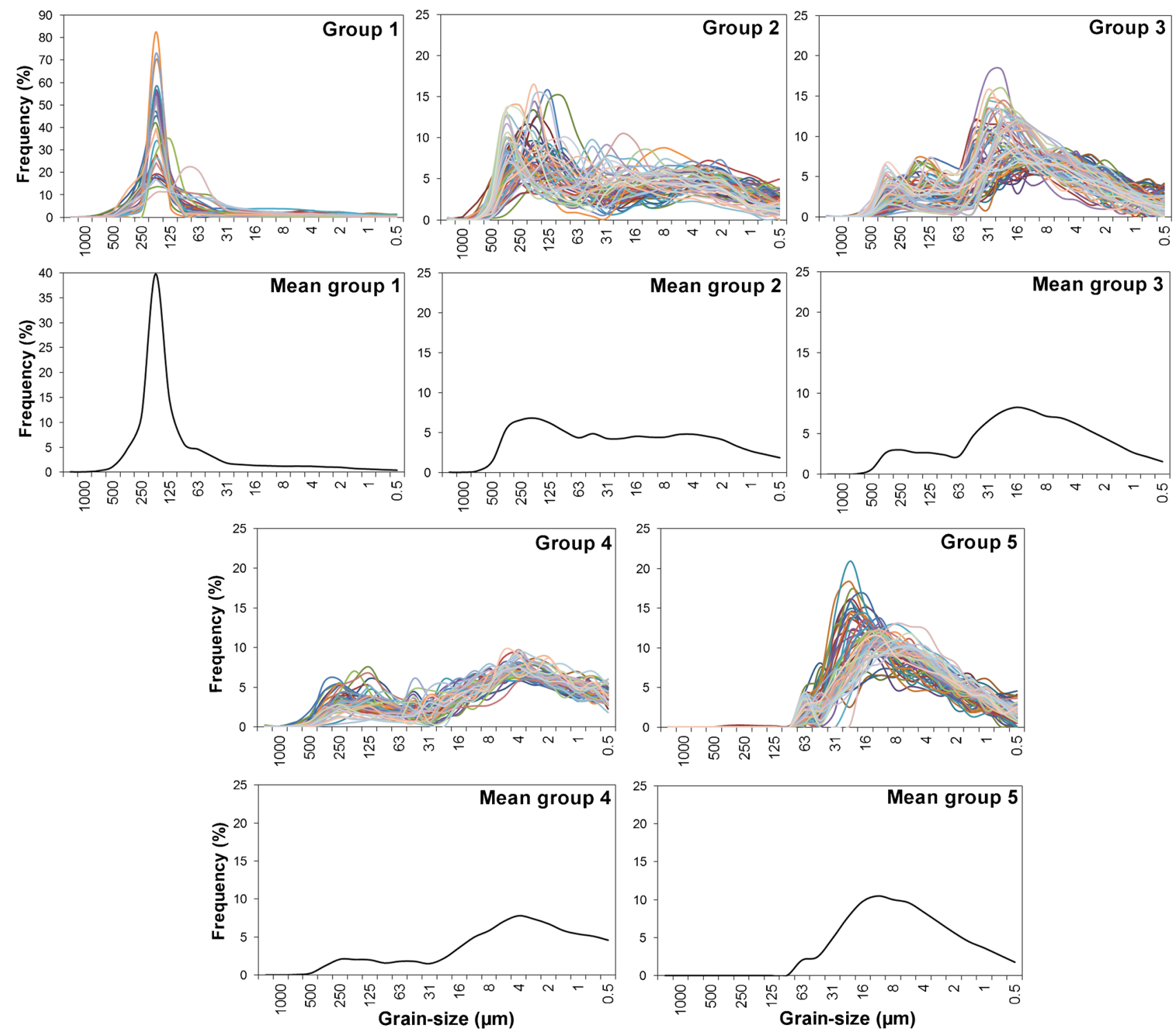

Figure 3. Grain-size distribution groups (textural facies) in LL and LV derived from EntropyMax: all distributions (above) and mean distributions (below). 
in order to ensure that each triangular element contains no more than one grab sampling point.

Water renewal time is a fundamental parameter for understanding chemical and ecological dynamics in lagoon environments and is also relevant to the supply of oxygen and the removal of pollution (Andrejev et al. 2004; Stamou et al. 2007). In this study, the local water renewal time (WRT) was computed by simulating the transport and diffusion of a conservative Eulerian tracer released uniformly throughout the entire lagoon with a concentration of 1 , while a concentration of zero was imposed on the seaward and freshwater boundaries. To simulate these processes in the Lesina and Varano lagoons the model solves the well known advection-diffusion equation, which, in 2D vertically integrated form, is given as:

$$
\frac{\partial C}{\partial t}+\frac{\partial u C}{\partial x}+\frac{\partial v C}{\partial y}=\frac{\partial}{\partial x}\left(K_{H} \frac{\partial C}{\partial x}\right)+\frac{\partial}{\partial y}\left(K_{H} \frac{\partial C}{\partial y}\right)
$$

where $C$ is the depth-integrated concentration of a passive tracer, $u$ and $v$ are the barotropic velocities and $K_{H}$ is the horizontal eddy diffusivity coefficient, set at a constant value of $3.7 \mathrm{~m}^{2} \mathrm{~s}^{-1}$ (Cucco and Umgiesser 2006). Fluxes through the bottom boundary are not considered here. The transport and diffusion equation is solved with an explicit time-step scheme; the advective part
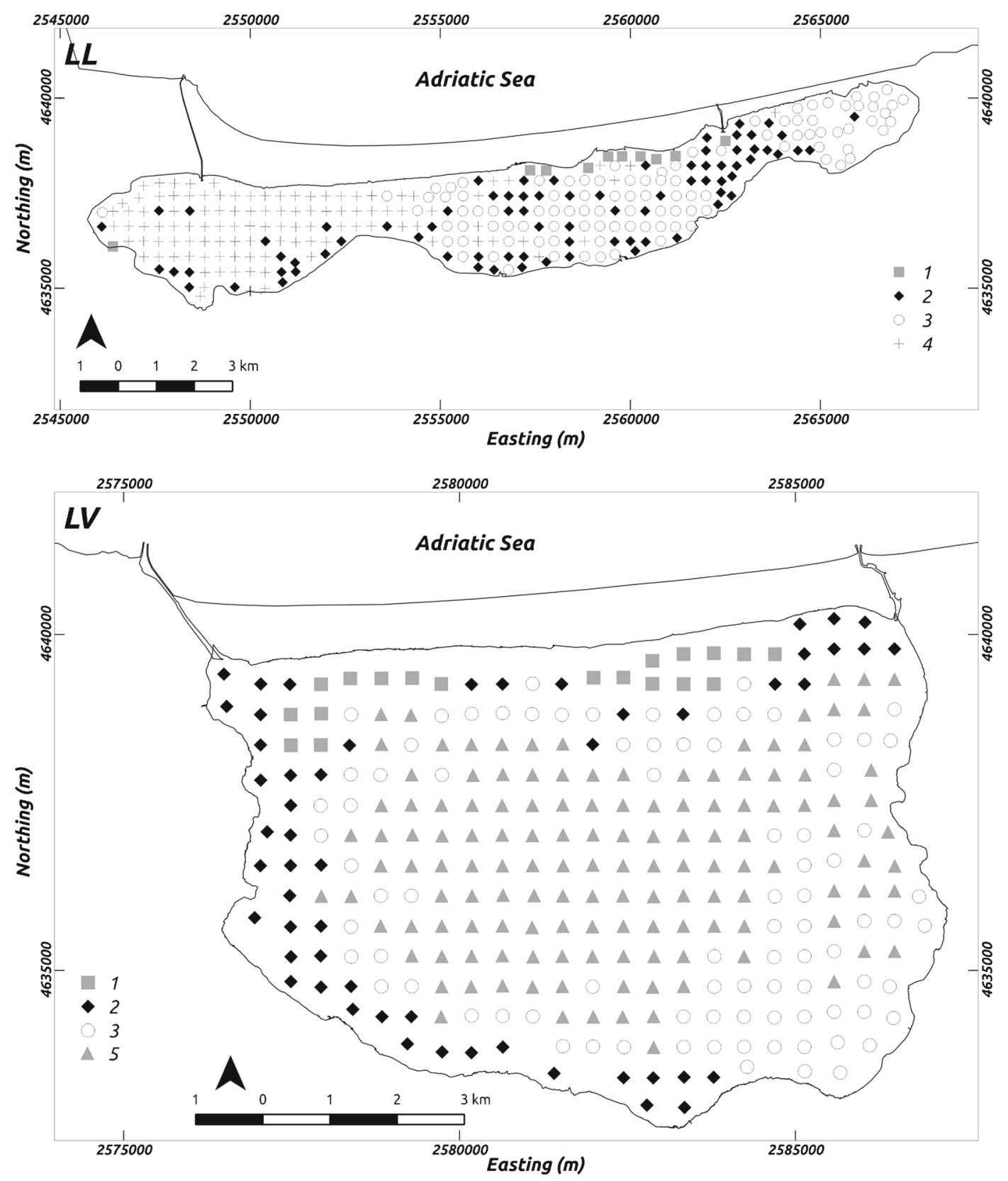

Figure 4. Areal distribution in LL and LV of sediment facies derived from EntropyMax. 
Table 1. Calinski-Harabasz (C-H) pseudo Fstatistic and Rs values for 25-interval $L L$ and $L V$ size data; optimal grouping is attained at peak $C-H$ and at point of reduced rate of change in Rs.

\begin{tabular}{lcc}
\hline $\begin{array}{l}\text { Number } \\
\text { of groups }\end{array}$ & $\begin{array}{c}\text { C-H pseudo } \\
\text { F-statistic }\end{array}$ & $R s$-values \\
\hline 2 & 188.39 & 35 \\
3 & 181.54 & 47 \\
4 & 248.71 & 60 \\
5 & 276.78 & 67 \\
6 & 237.53 & 69 \\
7 & 264.71 & 71 \\
8 & 261.47 & 73 \\
9 & 261.86 & 74 \\
10 & 196.16 & 75 \\
\hline
\end{tabular}

uses an upwind coefficient to ensure the exact conservation of mass.

Through advection and diffusion, lagoon water mass is mixed with new fresh water and is transported towards the open sea. The tracer mass in the system will thus decrease with time. Here we also consider the return of tracer mass into the lagoon. The local WRT is considered as the time required in each cell of the grid for the tracer concentration to fall to zero. More details about the hydrodynamic model and water renewal time computation can be found in Ferrarin et al. (2013a, 2014).

The model was applied to the lagoons using real forcing data. The model was used to simulate the evolution of a conservative tracer from June 2010 to August 2011 (May 2010 was used as the startup period). Open boundaries were treated with reference to water levels recorded in Vieste (located at about $30 \mathrm{~km}$ from the eastern end of LV) on the seaward side and to the fluxes of fresh water from the major tributaries indicated in figure 5 on the landward side. The numerical model has been already applied and validated for LL and the average uncertainty in WRT, estimated by a sensitivity study, is about $10 \%$ (Ferrarin et al. 2014). The application of the finite element model to LV is based on the same approach adopted for LL.

\subsection{Spatial interpolation}

The bathymetric data have a $5 \mathrm{~m}$ cell resolution and the maps were produced using the r.surf. contour algorithm (GRASS Development Team 2013) with a contour step of $0.2 \mathrm{~m}$. The WRT distribution maps were produced using the IDW interpolation algorithm (GRASS Development Team 2013) included in the GRASS GIS software (Neteler et al. 2012). The main factor affecting the accuracy of IDW is the value of the power parameter (Isaaks and Srivastava 1989), which in our case was set at 2. Data points classified by EntropyMax were switched from discrete points to homogeneous areas following a three-step approach: firstly creating a Voronoi diagram from the points; secondly interpolating the EntropyMax classes; thirdly assigning to the Voronoi regions the mean interpolated value.

The Voronoi diagram of a set of sites in the plane partitions the plane into regions called Voronoi regions, one to each site. The Voronoi region of a site $s$ is the set of points in the plane for which $s$ is the closest site (Fortune 1987). Using the v.voronoi algorithm (GRASS Development Team 2013), a tessellation of the two lagoons was created to spatialize in a discrete way the 'area of influence' of each sample.

The data points were then interpolated by regularized spline with tension (Mitasova and Mitas 1993) using the v.surf.rst algorithm (GRASS Development Team 2013). Spline methods are based on the assumption that the approximation function should pass as closely as possible to the data points and at the same time should be as smooth as possible. These two requirements can be combined into a single condition of minimizing the sum of the deviations from the measured points and the smoothness seminorm of the function (Mitasova et al. 1995). Finally, each Voronoi region was assigned the mean value of the interpolated raster and reassigned to the closest EntropyMax class. The two layers (WRT and grain-size classes) were then combined to produce the integrated maps, using the GRASS r.cross algorithm (GRASS Development Team 2013), which creates an output raster map layer representing all unique combinations of category values in the raster input layers.

The bathymetric data were not used in the classification per se, rather they were applied post-hoc to the results of the two-part raster calculation to provide a mean value for each zone. Spatial analysis was performed and spatial maps were created using QGIS (QGIS Development Team 2013).

\section{Results}

\subsection{Distribution of depths in the two lagoons}

Colour-shaded bathymetric maps for the two lagoons are shown in figure 1(a), while the distribution of specific depth categories is plotted in figure 1(b).

In LL the lagoon bed and the hydrodynamic conditions have been modified by the dredging of the two seaward channels and no intertidal marshes or intertidal mud flats are found. Overall, the distribution of depths is quite uniform: the western part of LL is slightly deeper than the rest, with depth values ranging between 1.2 and $1.6 \mathrm{~m}$, whilst the 

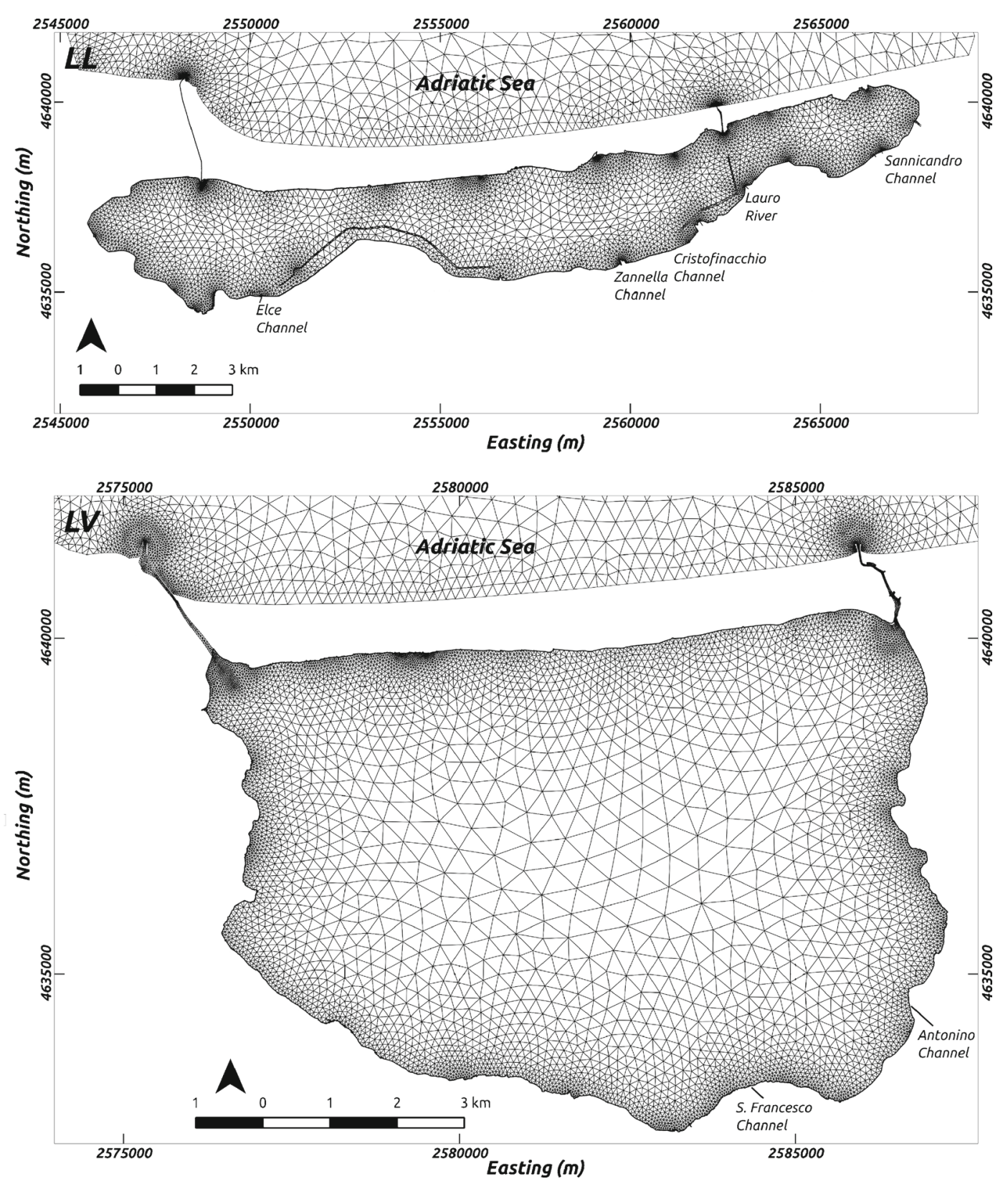

Figure 5. Computational finite element grids for Lesina and Varano lagoons.

eastern part has a mean depth of $0.8-1.0 \mathrm{~m}$. The deepest parts are two artificial channels, one south of the Schiapparo inlet, and another in the central part of the lagoon, parallel to the southern edge. They have mostly been filled in and the maximum depth is now $\sim 1.8 \mathrm{~m}$ compared to an original depth of 2 to $3 \mathrm{~m}$. The inlets connecting LL to the sea are $\sim 1.3 \mathrm{~m}$ deep.

LV does not have morphological features such as intertidal marshes, intertidal mud flats, submerged mud flats, and navigation channels. The isobaths of LV are quite regular, following the lagoon shore profile, with the maximum depth of the lagoon $(>4 \mathrm{~m})$ found in the central-southern part (figure 1a). The only exception to this general trend of the isobaths is a shallower area in the NE part of the lagoon, adjacent to the littoral. The two channels connecting LV to the sea (Varano and Capoiale) have a maximum depth of 4 and $5 \mathrm{~m}$, respectively.

To examine the morphology of LL and LV, the distribution of depths in terms of surface area (channels excluded) was calculated for each lagoon (figure 1b). A comparison of the two curves highlights a clear difference between the two lagoons. A modal depth of $1-1.2 \mathrm{~m}$ is evident in $\mathrm{LL}$ (figure $1 \mathrm{~b}$ ) and a higher modal value of $3-4 \mathrm{~m}$ in LV (figure 1b). The shallow basin of LL is characterised by a flat bed with depths that lie mostly within a narrow range $(0.8-1.6 \mathrm{~m})$, with $\sim 30 \%$ of 
the lagoon shallower than $1 \mathrm{~m}$. The Varano basin is characterised by a deep area in the range of 2.5 to $4.0 \mathrm{~m}(\sim 75 \%)$, with only $\sim 3 \%$ shallower than $1 \mathrm{~m}$.

\subsection{Comparison of the two lagoons: Ternary results}

The sediments of LL and LV are mostly composed of mud (79 and $83 \%$ of dry weight respectively). However, there are differences between the two lagoons with respect to the silt and clay fractions (LL: mean silt 51\%, mean clay 21\%; LV: mean silt $66 \%$, mean clay $17 \%$ ). The silt/clay ratio is therefore much lower in LL (mean 2.4) than in LV (mean 4.4).

The ternary plot shows that most of the samples from LV are composed of coarser sediment than the samples from LL (figure 2), although the silt fraction dominates over other fractions in both lagoons. The different textural properties of the sediments in the two lagoons indicate different hydrodynamic processes, and hence different depositional conditions, and different terrestrial sources.

Sediment composition is described by a diagonal band that gradually expands towards the silt-clay axis. However, in LL the textural gradient shows a shift towards lower silt/clay content. In LV, most of the sediments are richer in silt and sand. Most of the LL and LV sediment samples are classified as slightly sandy mud and mud. A small number of samples fall within the muddy sand category and a few are classified as slightly muddy sand or pure sand (figure 2).

In LL it can be seen that the sediments are dominated by slightly sandy mud, which covers almost all of the lagoon bed. Sandy mud and mud dominate the western part of the lagoon.

In LV, muddy sand and sandy mud create a centripetal band that covers the entire lake bed except for two areas, one at the southern edge and another in the eastern part, where slightly sandy mud and mud dominate. The size distribution of the sediments follows the typical lagoonal pattern: coarser sediments are found along the outer edges and finer ones towards the centre.

Given the generalised low sand and high mud content in the sedimentary environment of the two lagoons, the data was subjected to further investigation by EntropyMax analysis.

\subsection{EntropyMax results}

In order to better understand the role of bulk grain-size distributions rather than single grainsize intervals we applied EntropyMax analysis to the LL and LV samples. As the number of welldefined groups yielded by the software increases (starting from one), the $\mathrm{C}-\mathrm{H}$ statistic gradually increases until reaching a maximum value, after which it declines. For LL and LV, using 25 intervals per sample, the $\mathrm{C}-\mathrm{H}$ statistic peaked (indicating the best grouping solution) at five groups, further division showing a trend of decreasing $\mathrm{C}-\mathrm{H}$ values; this is also the point at which $R s$ showed a reduced rate of change (table 1 ).

The five groups of distributions resulting from the entropy analysis are displayed in figure 3, together with maps showing their location in the lagoons (figure 4). The groups are numbered from 1 (pure sand) to 5 (pure mud) with increasing mud content. The sedimentary facies corresponding to the five groups are as follows: (1) a clean, mediumto fine-grained sand $(\sim 150 \mu \mathrm{m}) ;(2)$ a bimodal muddy fine sand, containing a medium-grained sand mode $(\sim 200 \mu \mathrm{m})$ combined with subordinate amounts of mud; (3) a poorly sorted, medium- to coarse-grained sandy silt with a mode at $\sim 20 \mu \mathrm{m}$ and a tail of fine clay; (4) a very poorly sorted sandy mud, with sediments belonging to this group typically containing a primary mode at $4 \mu \mathrm{m}$ and a secondary medium- to fine-grained sand mode; and (5) a sorted unimodal silty mud $(\sim 10 \mu \mathrm{m})$.

In LL, the finest sediments (group 4) are found in the western to central sections, while the sandy silt (groups 2 and 3) accumulates mostly in the eastern and central areas. The coarser sediments (group 1) accumulate along the northern shoreline. In LV, finer sediments (group 5) prevail in the central part. The sites located along the northern shoreline have the coarsest composition (group 1). Muddy sand (group 2) accumulates all round the edge, while poorly sorted sandy silt (group 3) is found in a band near the central part of the lagoon and to the SE.

\subsection{Hydrological parameters}

LV shows a fairly uniform pattern of water renewal times. The highest values (280 days) are found in the central-southern part of the lagoon, while lower values characterise the area close to the edge and near the connecting channels (bottom panel in figure 6). LV has a basin-wide average water renewal time of $\sim 260$ days. These are the first model-derived data to be published for LV and are considerably lower than previously published flushing time estimates, which ranged from 500 (Specchiulli et al. 2008) to 1000 days (Manini et al. 2002), i.e., 2 to 4 times higher than our data. In contrast, as described in Ferrarin et al. (2014), LL shows a pronounced west-east WRT gradient, with a basin-wide average of $\sim 190$ days (top panel in figure 6), i.e., 2-3 times higher than previous data reported by Manini et al. (2002) and Brugnano et al. (2011), who, on the basis of simple 

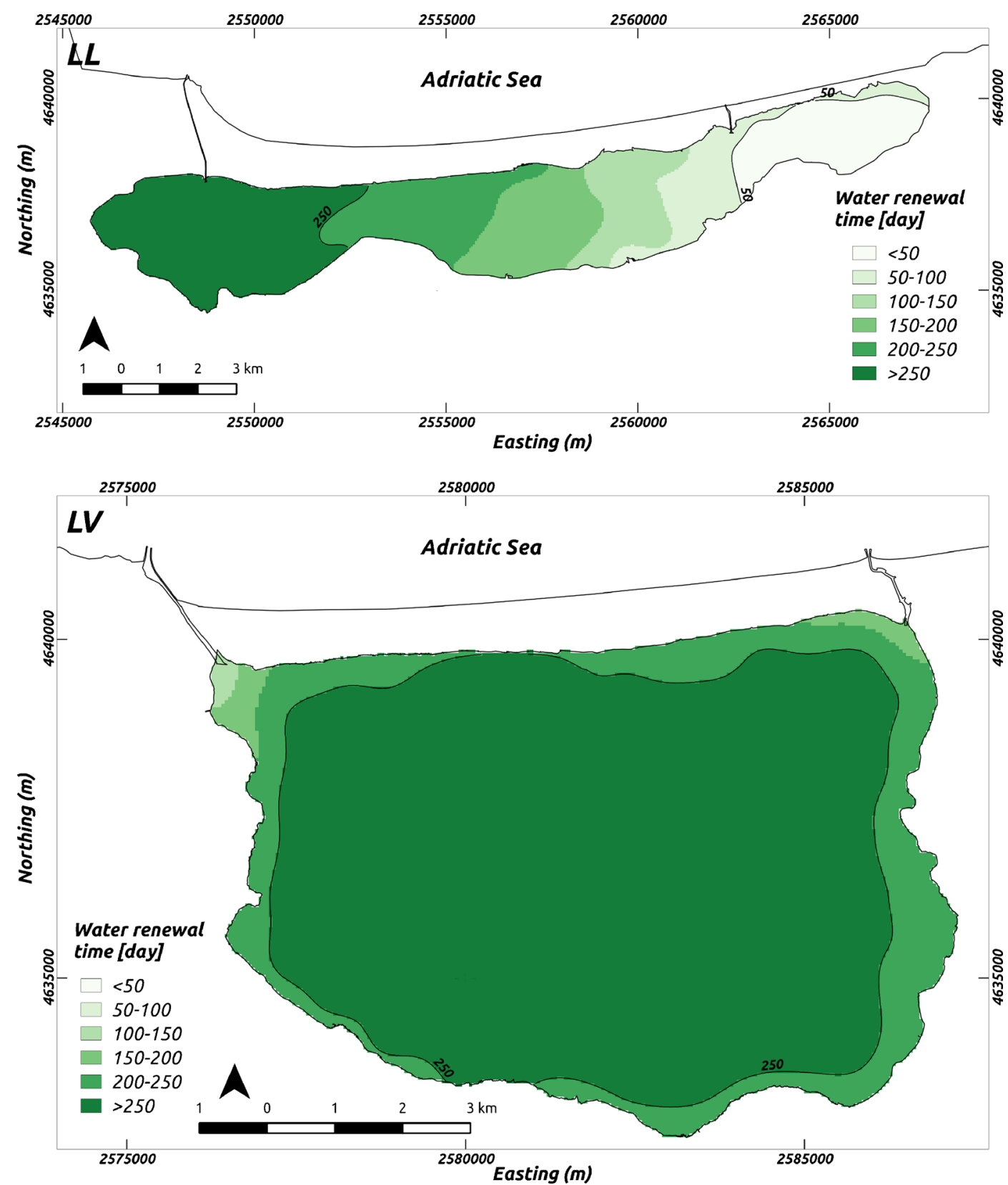

Figure 6. Distribution of water renewal time (days) in LL and LV.

assumptions estimated the average flushing time of LL to be $\sim 70-100$ days.

\subsection{Classified map creation: EntropyMax and WRT}

On the basis of the previously described detailed mapping of grain-size facies and WRT-model results, it is possible to create integrated hydrogranulometric classes for the LL and LV on a scale that is helpful for studying the various processes (Molinaroli et al. 2007, 2009a).

Pearson's correlation analysis (2 tailed) of sediment facies at each of the 300 grab sampling points showed significant correlation $(p<0.001)$ with both the WRT and depth values at the same sample stations. For LL, sediment facies correlated more strongly with WRT $(r=0.49)$ than with depth $(r=0.20)$, whilst the opposite trend was seen in LV (WRT, $r=0.33$; depth, $r=$ $0.60)$. In order to produce an integrated classification of abiotic parameters we first spazialised the sedimentary facies of LL and LV, switching from discrete points to homogeneous areas. We then integrated the WRT maps with these new EntropyMax areas using the procedure described in section 3.5 (spatial interpolation). The limit values used to classify the WRT maps for LL were 90 and 270 days (1st and 3rd percentile). For LV the 
values used were 220 (this being the value that best identified the two areas influenced by the seaward channels) and 255 days (1st percentile). The integration produced a splitting of facies 2,3 and 4 in LL, and facies 2, 3 and 5 in LV, into two different classes each, making a total of nine classes in all, with seven found in LL and seven in LV (figure 7 and table 2).

\subsubsection{Lagoon of Lesina}

Class \#1 is a medium- to fine-grained sand $(150 \mu \mathrm{m})$ covering two small areas ( $\sim 3 \%$ of the lagoon) parallel to the northern coast, west of the eastern seaward inlet (Schiapparo), with intermediate WRT values of 100-150 days and a mean depth of $0.6 \mathrm{~m}$.

Class \#2 is a bimodal muddy fine sand, distributed all along the southern edge of the lagoon and in a small area in the eastern part of LL. It covers $\sim 30 \%$ of the lagoon and spans a wide range of WRT values. Class 2 was subdivided into subclass $2 \mathrm{a}$, found in a band to the east, between the Lauro river and Schiapparo inlet, with $\mathrm{WRT}<100$ days, and subclass $2 \mathrm{~b}$, found in patches along the southern edge of the lagoon (near the terrestrial inputs) and in a small area behind the sand barrier, west of the Schiapparo inlet.

Class \#3 is poorly sorted and bimodal, with $\sim 20 \%$ sand, a mode at $20 \mu \mathrm{m}$ and a tail of fine clay. Class 3 sediments cover almost $40 \%$ of the lagoon and are concentrated in the central and eastern parts, where WRT values vary widely. We therefore subdivided this class into two subclasses: $3 \mathrm{a}$ in the eastern part has low WRT values ( $<50$ days), and a mean depth of $0.5 \mathrm{~m}$. With an area of more than $6 \mathrm{~km}^{2}$ ( $\sim 12 \%$ of the lagoon) it is characterized by a wetland with dense reed beds and clear ponds. Subclass $3 \mathrm{~b}$ is mostly found in the central part of LL ( $\sim 25 \%$ of the lagoon), with intermediate to high WRT values (100-200 days) and a mean depth of $\sim 1 \mathrm{~m}$.

Class \#4 is a poorly sorted mud with $10 \%$ sand. It covers $\sim 33 \%$ of the lagoon and is concentrated on the western side, associated with high WRT values (>200 days) and, in part, with relatively deeper waters. The integration of class 4 samples with WRT values generated two subzones, one (class \#4a) in the central-western part $(\sim 13 \%$ of the lagoon), with WRT values of $\sim 150-250$ days and a mean depth of $\sim 1 \mathrm{~m}$, and another at the western end (class \#4b, $20 \%$ of the total lagoon), characterized by the highest WRT values ( $>270$ days) and corresponding to the deepest part of the lagoon (up to $1.6 \mathrm{~m})$.

The size of the different classes ranges from less than $2 \mathrm{~km}^{2}$ for class 1 to $\sim 12 \mathrm{~km}^{2}$ for class $3 \mathrm{~b}$.

\subsubsection{Lagoon of Varano}

Four of the five sedimentary facies extracted by EntropyMax are present in LV, with facies \#5 instead of LL facies \#4 representing the finest endmember: the distribution of most of the classes is somewhat concentric, from the shoreline to the middle of LV, following the isobaths. The integration of EntropyMax results with WRT distribution produced the following results:

Class \#1 is very similar to its counterpart in LL, a medium- to fine-grained sand $(150 \mu \mathrm{m})$, and is found in two elongated areas parallel to the coastal barrier that separates Varano from the Adriatic Sea. It covers a relatively small area $(\sim 10 \%)$ between the two seaward inlets, Capoiale and Varano, with WRT values of 200-250 days and depths of $0.5-2.0 \mathrm{~m}$.

Class \#2 is a bimodal muddy fine sand, covering $\sim 17 \%$ of the lagoon. The interpolation with WRT determined two subclasses, one (class 2a) distributed in two small areas $(\sim 3 \%$ of the total) near the connections to the sea, with WRT values $<220$ days, and another (class $2 b$ ) occupying a $1 \mathrm{~km}$-wide belt all around the western and southern borders of LV, with higher WRT values.

Class \#3 represents a poorly sorted sediment, bimodal with $\sim 20 \%$ sand, a mode at $20 \mu \mathrm{m}$ and a tail of fine clay. Class 3 sediments cover more than $30 \%$ of the lagoon around the central part (which is also the deepest) and on the south-eastern side of the lagoon, where a broad range of WRT and depth values are found. This was thus subdivided into two subclasses: $3 \mathrm{a}$ and $3 \mathrm{~b}$. Class \#3a ( $6 \%$ of the lagoon) is found in the south-eastern part of LV, with relatively short WRT values (less than 250 days) and a mean depth of $\sim 2.5 \mathrm{~m}$. On the other hand, sediments belonging to class $3 \mathrm{~b}(\sim 25 \%$ of the lagoon) have slightly higher WRT values ( $>250$ days) and are deeper $(2.5-3.5 \mathrm{~m})$ than class $3 \mathrm{a}$; they surround the deep central part of LV on the south, west and north sides.

Class \#5 is a well sorted silty mud (mode 10 $\mu \mathrm{m})$. It covers $\sim 45 \%$ of the lagoon and represents the most stable facies of the two studied lagoons. It is mainly associated with the highest WRT values (>250 days) and is more than $3 \mathrm{~m}$ deep. The integration of class 5 samples with WRT values generated two subzones. Class $5 \mathrm{a}$ is a small area $(\sim 3 \%$ of the lagoon) concentrated in the relatively more dynamic eastern side of LV with WRT values of 200-250 days and a mean depth of $\sim 2.5 \mathrm{~m}$. Class $5 \mathrm{~b}$ is found in the centre ( $\sim 40 \%$ of the lagoon), characterized by the highest WRT values ( $>250$ days) and the greatest depths $(>3.5 \mathrm{~m})$.

The size of the different classes ranges from $\sim 2 \mathrm{~km}^{2}$ for class $2 \mathrm{a}$ and $5 \mathrm{a}$ to more than $25 \mathrm{~km}^{2}$ for $5 \mathrm{~b}$. 

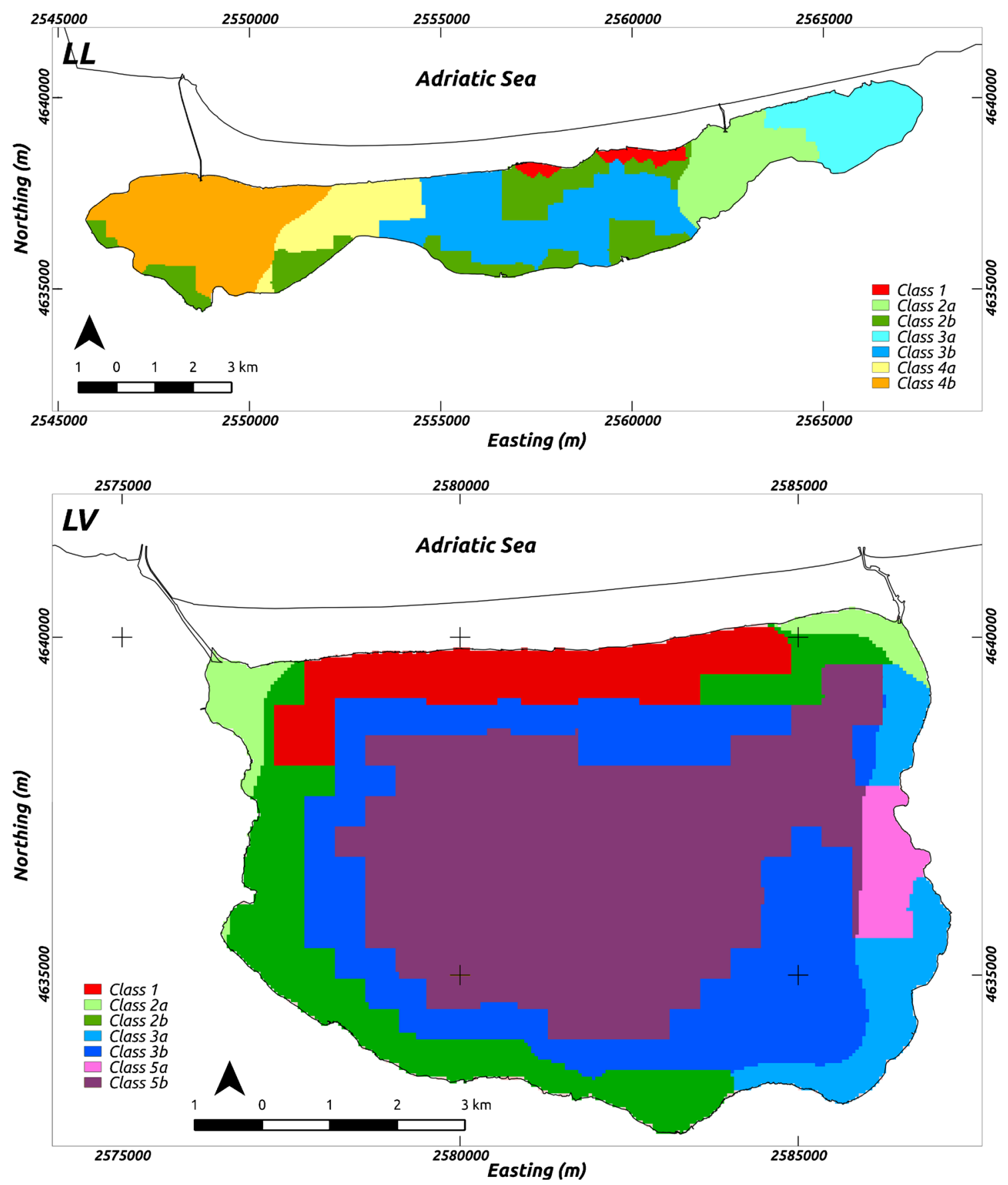

Figure 7. Composite map of integrated sediment classes in LL and LV. Numbers indicate combinations and corresponding zones.

\section{Discussion}

\subsection{Bathymetry and grain size}

Bathymetric and grain size data have been already published by Specchiulli et al. (2010) for LL and LV and Frontalini et al. (2013) for LV. The data were derived from $\sim 15$ samples in both lagoons by Specchiulli and coworkers (2010) and $~ 50$ sampling sites in LV by Frontalini et al. (2013). The new bathymetric maps produced by this study used more than $250 \mathrm{~km}$ of acquisition profiles and the distribution and composition of the LL and LV bottom sediments were analysed on the basis of grain-size data from 300 sites. The average bathymetry was found to be slightly deeper than previously published data (Specchiulli et al. 2010) for LL $(1.0 \mathrm{~m}$ vs. $0.8 \mathrm{~m})$ and slightly shallower for LV $(3.2 \mathrm{~m}$ vs. $4.0 \mathrm{~m})$. The surficial bottom sediments of LL and LV are heterogenous and mostly composed of mud $(\geq 80 \%)$, confirming the data of Specchiulli et al. (2010) for both LL and LV. 
Table 2. Essential data for sediment classes identified in each lagoon (LL and LV). Numbers indicate corresponding areas in figure 7. Second column shows percentage of lagoon area covered by each class.

\begin{tabular}{|c|c|c|c|}
\hline Class & $\%$ Area & EntropyMax facies & Source/input/condition \\
\hline \multicolumn{4}{|c|}{ Lesina } \\
\hline 1 & 3 & Medium- to fine-grained sand $(150 \mu \mathrm{m})$ & Marine input \\
\hline $2 \mathrm{a}$ & 10 & Bimodal muddy fine sand & Terrestrial and marine sources \\
\hline $2 \mathrm{~b}$ & 18 & (sand mode $200 \mu \mathrm{m}$, mud) & Proximal terrestrial sources \\
\hline $3 \mathrm{a}$ & 12 & Poorly sorted, medium- to coarse-grained & Stable/unstable conditions: strong dynamics \\
\hline $3 b$ & 24 & sandy silt (mode at $20 \mu \mathrm{m}$, tail of fine clay) & Stable/unstable conditions: weak dynamics \\
\hline $4 \mathrm{a}$ & 13 & Poorly sorted sandy mud (fine mode at $4 \mu \mathrm{m}$, & Urban and aquaculture discharges: strong dynamics \\
\hline $4 \mathrm{~b}$ & 20 & medium- to fine-grained sand mode) & Cattle farm and aquaculture discharges: confinement \\
\hline \multicolumn{4}{|c|}{ Varano } \\
\hline 1 & 9 & Medium- to fine-grained sand $(150 \mu \mathrm{m})$ & Marine input \\
\hline $2 \mathrm{a}$ & 3 & Bimodal muddy fine sand & Terrestrial and marine sources \\
\hline $2 \mathrm{~b}$ & 14 & (sand mode $200 \mu \mathrm{m}, \mathrm{mud}$ ) & Proximal terrestrial sources \\
\hline $3 \mathrm{a}$ & 6 & Poorly sorted, medium- to coarse-grained sandy & Stable/unstable conditions: strong dynamics \\
\hline $3 \mathrm{~b}$ & 25 & silt (mode at $20 \mu \mathrm{m}$, tail of fine clay) & Stable/unstable conditions: freshwater springs \\
\hline $5 \mathrm{a}$ & 3 & Sorted unimodal silty mud (mode at $10 \mu \mathrm{m}$ ) & $\begin{array}{l}\text { Stable mud facies/slightly stronger } \\
\text { dynamics } \rightarrow \text { coarser mode }\end{array}$ \\
\hline $5 \mathrm{~b}$ & 40 & & Stable mud facies/stratification \\
\hline
\end{tabular}

Frontalini et al. (2013) found much less mud $(\sim 50 \%)$ in LV compared to our survey, probably due to analytical differences in sample treatment, which did not take account of flocculation, thus overestimating the coarse fractions.

The relationships between bathymetry and sediment texture, as well as between sedimentology and hydrology, have been already studied in the Lagoon of Venice (Molinaroli et al. 2007, 2009a) and Lagoon of Cabras (Molinaroli et al. 2009b). The detailed bathymetric charts produced for LL and LV in the present study showed similarities to sub-basin A of the Lagoon of Venice and to the Lagoon of Cabras, located near the Gulf of Oristano, respectively. Indeed, LL is a shallow basin similar to the northernmost basin of the Lagoon of Venice (sub-basin A: average water depth $\sim 1 \mathrm{~m}$ ) (Molinaroli et al. 2009a). Considering just the shallow lagoonal flats of the latter, the two environments are quite similar in both size (LL: $51 \mathrm{~km}^{2}$; sub-basin A: $64 \mathrm{~km}^{2}$ ) and sedimentary facies (clay/silt ratio: 0.5 in LL; 0.6 in sub-basin A). LV is rather similar to the Lagoon of Cabras, located near the Gulf of Oristano (Molinaroli et al. 2009b). Both lagoons are characteristically bowlshaped at the centre; they have different surface areas (LV: $65 \mathrm{~km}^{2}$; Lagoon of Cabras: $22 \mathrm{~km}^{2}$ ) but moderately similar depth (LV: average $\sim 3 \mathrm{~m}$; Lagoon of Cabras: average $\sim 2 \mathrm{~m}$ ). From a sedimentological point of view both lagoons show high silt content (LV: 65\%; Lagoon of Cabras: 60\%).

In addition to the traditional textural classification, the ability of the EntropyMax analysis to recognise discrete groups with similar granulometric properties made it possible to compare and contrast the sedimentary facies of the two lagoons. Poorly sorted bimodal sediments (groups 2 and 3 ) are frequent in both lagoons. In contrast, poorly sorted sandy mud (group 4) was found only in LL, while sorted unimodal silty mud (group 5) was found only in LV.

The characterisation of mud and sand facies highlighted by the EntropyMax analysis in the sedimentary environment of the two lagoons may be useful for habitat suitability modelling.

\subsection{Hydrological parameters}

In this study, the parameter used to describe the hydrological characteristics of the lagoons is water renewal time (WRT). The average WRT values and spatial distributions reflect the different hydrological conditions in the two lagoons. The water volume of LV is more than four times that of LL (1.97 vs. $\left.0.4510^{8} \mathrm{~m}^{3}\right)$. Therefore, although sea-lagoon water exchange in $\mathrm{LV}$ is three times that of $\mathrm{LL}$ (about 30 vs. $10 \mathrm{~m}^{3} \mathrm{~s}^{-1}$ ), the basin-wide average WRT of LV is still higher than that of LL (260 vs. 190 days). Freshwater inputs are considerable in LL (about $4.5 \mathrm{~m}^{3} \mathrm{~s}^{-1}$, mostly concentrated in the eastern region) and influence the water renewal capacity of the lagoon, creating a well-defined west-east WRT gradient (Ferrarin et al. 2014). In contrast, renewal capacity in LV is mainly controlled by sealagoon fluxes, while the scarce freshwater inputs (less than $1 \mathrm{~m}^{3} \mathrm{~s}^{-1}$ ) do not significantly influence the spatial distribution of WRT.

Kjerfve (1986) subdivided coastal lagoons into three geomorphic types according to water 
exchange with the sea: leaky lagoons, restricted lagoons, and choked lagoons. In accordance with this classification, Roselli et al. (2013) recently classified LL and LV as 'restricted lagoons'. However, due to their long water renewal times and according to Ferrarin et al. (2013b), they may merit an intermediate classification between restricted and choked.

\subsection{Classified maps}

The relationships between hydrodynamic parameters and grain size in two contrasting transitional environments, like the ones studied in the present paper (LL and LV) have already been considered by Molinaroli and coworkers (2009a, b), who compared the Lagoons of Venice and Cabras. Those authors found a good correlation between WRT and fine fractions $(<8 \mu \mathrm{m})$ classified following a traditional textural classification, but did not perform EntropyMax analysis. As a further methodological improvement on Molinaroli et al. (2009a, b) we integrated the WRT maps with the new EntropyMax sedimentary facies maps. The nine classes obtained, seven of which were observed in LL and seven in LV, were spatially compared to macrobenthos and foraminiferal assemblages and zooplankton distribution in the two lagoons as described by various authors.

\subsubsection{Lagoon of Lesina}

Class \#1 appears to be associated with marine sources. The highest zooplankton diversity indices were found in this area, due to the co-occurrence of species of lagoon and marine origin (Brugnano et al. 2011).

Class \#2 appears to be associated with proximal sources. Subclass $2 a$ is in the eastern zone, in a belt $5 \mathrm{~km}$ wide where marine and terrestrial inputs (agricultural discharge) often mix (mean WRT values $<100$ days). The macrozoobenthic communities of this area were studied by Specchiulli et al. (2010), who, in summer 2007, found it had the lowest number of individuals and low species diversity. In the same area Marzano et al. (2003) found the highest abundance and the lowest diversity values on an annual basis. Class $2 b$ is distributed in patches in the southwestern part of the lagoon, where it is mainly associated with urban inputs, and in the central part, where it is near inputs from canals and small rivers carrying agricultural discharge. It is also present in a small area west of the Schiapparo inlet, behind the sand barrier, where the possibility of inputs of seawater (and sediments) through five buried ancient seaward channels was raised by Ferrarin and coworkers (2013a).
Class \#3 represents an intermediate sediment, mainly occurring along a gradient from relatively stable to relatively unstable conditions. Subclass $3 \mathrm{a}$ is associated with a wetland with dense reed beds and clear pools and coincides with a Natural Reserve designated in 1981, an area of animal repopulation of fundamental importance for many species of birds. Subclass $3 \mathrm{~b}$ is mostly found in the central part of LL, which in the period 2000-2003 saw the formation of thick mats of the macroalga Valonia aegagropila on the soft bottoms, affecting the structure of zoobenthic communities; it was demonstrated that the presence of the alga was more important than hydrological parameters in segregating this area from the rest of the lagoon (Marzano et al. 2003). A few years later Specchiulli et al. (2010) did not find Valonia but observed a decreasing west-east gradient of macrobenthic abundances. Despite the relatively high WRT values, class $4 \mathrm{a}$ is characterised by high dynamics due to wind and currents and often has medium-to-high numbers of individuals and high diversity indices for macrobenthic communities, with a prevalence of Bivalvia (Specchiulli et al. 2010). Class 4b is concentrated in the most confined part of the lagoon, where high salinity values and progressive nutrient enrichment over the last 30 years have led to a succession of uniform carpets of macroalgae, from Gracilaria sp. to Cladophora sp. and Valonia sp., which have occasionally caused dystrophic crises (Manini et al. 2003; Roselli et al. 2009). This area is affected by several human activities, i.e., aquaculture, livestock rearing and urban discharges. In this part of LL Specchiulli and coworkers (2010) found that the high sediment organic load (TOC), associated with the prevalent fine fraction, affected the structure of macrobenthic communities, leading to decreased values for both abundance and diversity. This area can be described as a 'detritus trap' due to its ability to retain all organic $\mathrm{C}$ inputs, and was recently chosen for bioremediation experiments (D'Errico et al. 2013).

This is probably the most vulnerable part of LL. In summer 2008, climatic conditions led to the hydrological isolation of the western basin, producing a dystrophic crisis and a shift from a macrophyte-based system to a phytoplanktonbased system (Vignes et al. 2009).

\subsubsection{Lagoon of Varano}

Four of the five sedimentary facies extracted by EntropyMax are present in LV, with facies \#5 instead of LL facies \#4 representing the finest end-member.

Class \#1 is very similar to its equivalent in LL, and appears to be associated with marine 
sources. Specchiulli et al. (2010) showed that current dynamics are more active in the northernouter margins near the two channels and detected stressed sites along the northern shoreline of LV with high sand content. Most of the fishing concessions, especially for the harvesting of Tapes philippinarum, are found in this northern area, representing a further source of disturbance.

Class \#2 appears to be associated with proximal sources (terrestrial or marine). Two small areas of subclass 2 a receive marine inputs as sandy sediments from the two channels, and the more easterly one is probably also affected by a drainage pumping station. In these two areas, Frontalini and coworkers (2013) found a characteristic foraminiferal biotope, defined as an Intermediate Marine subbiotope, with the highest abundance of A tepida, A. parkinsoniana, A. beccarii, and A. perlucida and the greatest diversity. Near the western and southern shores of the lagoon, subclass $2 \mathrm{~b}$, a muddy fine sand, is mainly associated with freshwater inputs, and in the southern part with input from livestock rearing and the town of Cagnano (Renzi et al. 2012). Specchiulli and coworkers (2010) found high numbers of macrozoobenthic individuals (2000-3000 ind $\cdot \mathrm{m}^{-2}$ ) along the western shoreline.

Class \#3 sediments occur mainly along a gradient from relatively stable to relatively unstable conditions. A small area with class 3a sediments is found to the north-east, near the mouth of the Varano channel, and its instability is confirmed by the different foraminiferal assemblages found by Frontalini et al. (2013) at stations within a short distance of each other. In the southeastern part of LV, which has sediment of both class 3a (near the shoreline) and 3b (deeper, with higher WRT), Specchiulli and coworkers (2010) found the highest macrofaunal diversity indices, associated with two wastewater drains rich in phosphorus. Frontalini et al. (2013) found high diversity values for foraminiferal assemblages as well, and this group of stations were defined as an Inner Marginal Lake Biotope. In the western part, with sediment belonging to subclass $3 \mathrm{~b}$, Belmonte et al. (2011) found freshwater species (Daphnia sp., Calanipeda aquaedulcis, Rotifera), probably due to its proximity to freshwater springs.

Class \#5 represents the most stable facies of the two studied lagoons. A small area $\left(<2 \mathrm{~km}^{2}\right)$ near the eastern shore with lower water residence time belongs to class 5a. Belmonte et al. (2011) found several organisms of marine origin on the eastern side of LV (subclass 5a), confirming the relatively high water dynamics. Again, on the eastern side Specchiulli et al. (2010) found high species richness with Polychaetes (Perinereis cultrifera) prevailing over Bivalvia (Loripes lacteus). In contrast, the same authors found the lowest abundances and diversity indices in the central part of LV (class 5b). Similar findings are reported by Belmonte et al. (2011), who found broadly similar zooplankton community composition in the eastern and central areas of LV, although the central area had the lowest abundances. He found high densities of the jellyfish Aurelia Aurita, proposing that enclosed habitats characterised by calm waters and high food availability enhanced the probability of jellyfish survival. Specchiulli et al. (2010) found much lower abundance of Musculista senhousia in subclass $5 \mathrm{~b}$ (central lagoon) than both the western and eastern sides of the lagoon, due to summer hypoxia and anoxia. This result suggests that when coupled with low water exchange and high temperatures in summer, organic matter decomposition processes promote more rapid oxygen depletion in the central part of LV than in other areas (Specchiulli et al. 2010). In this area Specchiulli et al. (2008) showed an increase in ammonia with temperature due to remineralising processes.

In summary, the nine classes obtained by integrating the five facies of the EntropyMax analysis with the model-derived WRT values highlighted similarities and differences between LL and LV. By comparing the classes with published data it is seen that class 1 is of marine origin in both lagoons, with relatively low WRT values and relatively shallow depths. Class 1 in LV also deserves attention due to the increasing intensity of Tapes philippinarum harvesting. Class 2 indicated proximal terrestrial sources with some inputs from the sea. Class 3 was clearly distributed along a west-east gradient in LL (following WRT values), class 3a coinciding with the Lesina Natural Reserve, of great ecological importance, and thus confirming the association of good environmental quality with strong hydrodynamics (the lowest WRT values, $<50$ days). In spite of their sedimentological and hydrodynamic differences, classes 2 and 3 in LV sustain biological communities with higher diversity and species richness than the central area of LV. Class $4 \mathrm{~b}$, on the western side of LL, and class $5 \mathrm{~b}$, in the centre of LV, were associated with the highest mud content and the highest WRT values, making them the most vulnerable to eutrophication effects, particularly the sedimentation of organic matter. A specific focus on the welfare of these areas may therefore be advisable.

The size of the different classes ranges from less than $2 \mathrm{~km}^{2}$ for class 1 in LL and $5 \mathrm{a}$ in LV to more than $25 \mathrm{~km}^{2}$ for $5 \mathrm{~b}$ in LV: spatial scales that are comparable to the variation of benthic assemblages (macrophytes and fish), which were found to vary along the confinement gradient at a scale of $10^{0}-10^{1} \mathrm{~km}$ in Mar Menor (Pérez-Ruzafa et al. 2007a). 
Comparison of human impact across lagoons is hindered by high-scale variability of hydrographical and geomorphological features; as Pérez Ruzafa et al. (2007b) suggested, one way of dealing with this is to establish a monitoring plan for each class found in LL and LV, with special attention to the more vulnerable areas.

\section{Conclusions}

In semi-closed shallow coastal environments, like LL and LV, where local ecosystem conditions depend on the dynamics of the whole basin, areas with longer renewal times exhibit a higher degree of eutrophication and saprobity, defined as the state of the environment resulting from the input and decomposition of organic matter and the removal of its catabolites (Tagliapietra et al. 2012), than those with shorter times. Consequently, the spatial distribution of water renewal time, together with sediment characteristics, could help to explain the heterogeneous spatial distributions of benthic assemblages and trace elements found in the sediments of these lagoons. Indeed, an additional benefit of these models is that the resolution can be tailored to provide detailed information at points of interest, i.e., where grab samples are collected.

With these maps, we explored the potential relationships between physical and biological parameters. In some cases, we discovered a clear match between abiotic classification and biota; in others, however, relationships were more difficult to discern and require further investigation.

Specifically the following points can be listed as main conclusions:

- New bathymetric charts of LL and LV were produced which described in detail the geophysical characteristics of the two basins: the mean depth of LL is $\sim 1 \mathrm{~m}(\sim 30 \%$ is shallower than $1 \mathrm{~m})$ whilst the mean depth of $\mathrm{LV}$ is $\sim 3 \mathrm{~m}(\sim 3 \%$ is shallower than $1 \mathrm{~m}$ ).

- In LL and LV, five sediment facies were identified: (1) a clean, medium- to fine-grained sand; (2) a bimodal muddy fine sand, containing a medium-grained sand mode combined with subordinate amounts of mud; (3) a poorly sorted, medium- to coarse-grained sandy silt; (4) a very poorly sorted sandy mud; and (5) a sorted unimodal silty mud. The poorly sorted sandy mud (facies 4) was found only in LL and the sorted unimodal silty mud (facies 5) only in LV.

- LL is characterised by high variability of water renewal times (from $\sim 2$ to 291 days). In LV water renewal times are more uniform (from 134 to $\sim 281$ days). The waters in the eastern part of LL and the area near the shoreline of LV are replaced more rapidly than the western and deeper parts of the two lagoons.

- The combination of sedimentological (grain-size) and hydrological (water renewal time) data produced an integrated classification of abiotic parameters that is useful for identifying vulnerable areas already suffering from environmental problems. Indeed, facies 4 and 5, characterized by WRT $>250$ and fine sediments, correspond to areas where dystrophic events have been observed in both lagoons in recent years.

- The importance (weight) of each abiotic parameter in the classification is different for the two lagoons. Comparison with recent results (biotic and abiotic data) obtained in the two lagoons shows that hydrodynamics is the forcing factor for zonation in LL, while sediment properties play the main role in $\mathrm{LV}$.

- Although this study makes many simplifications, the integrated abiotic classification should provide the coastal management community with new insight into the dynamics of estuarine and transitional environments. The methods will be applicable to most large Mediterranean coastal lagoons and to a variety of transitional and coastal environments.

\section{Acknowledgements}

The useful comments of Alex Callaway and two anonymous reviewers are kindly acknowledged. Stefano Menegon provided invaluable assistance in preparing maps and plots. Mr. George Metcalf revised the English text. Supplementary information with the database is available at the link: http://dx.doi.org/10.6084/m9.figshare.1044121.

\section{References}

Anderson J, Van Holliday D, Kloser R, Reid D and Simard Y 2008 Acoustic seabed classification: Current practice and future directions; ICES J. Mar. Sci. 65 1004-1011.

Andrejev O, Myrbergk A and Lundberg P A 2004 Age and renewal time of water masses in a semi-enclosed basinapplication to the Gulf of Finlan; Tellus 56A 548-558.

Barbone E and Basset A 2010 Hydrological constraints to macrobenthic fauna biodiversity in transitional waters ecosystems; Rend. Fis. Acc. Lincei 21 301-314.

Basset A, Sabetta L, Fonnesu A, Mouillot D, Do Chi T, Viaroli P, Giordani G, Reizopoulou S, Abbiati M and Carrada G C 2006 Typology in Mediterranean transitional waters: New challenges and perspectives; Aqautic Conserv: Mar. Freshw. Ecosyst. 16 441-455.

Belmonte G, Scirocco T and Denitto F 2011 Zooplankton composition in Lake Varano (Adriatic Sea coast, Italy); Italian J. Zoology 78 370-378.

Bosellini A, Morsilli M and Neri C 1999 Long-term event stratigraphy of the Apulia Platform margin (Upper Jurassic to Eocene, Gargano, Southern Italy); J. Sedim. Res. 69 1241-1252. 
Brown C J, Smith S J, Lawton P and Anderson J T 2011 Benthic habitat mapping: A review of progress towards improved understanding of the spatial ecology of the seafloor using acoustic techniques; Estuarine Coast. Shelf Sci. 92 502-520.

Brugnano C, D'Adamo R, Fabbrocini A, Granata A and Zagami G 2011 Zooplankton responses to hydrological and trophic variability in a Mediterranean coastal ecosystem (Lesina Lagoon, South Adriatic Sea); Chem. Ecol. 27 461-480.

Caroppo C 2000 The contribution of picophytoplankton to community structure in a Mediterranean brackish environment; J. Plankton Res. 22 381-397.

Cogan C, Todd B, Lawton P and Noji T 2009 The role of marine habitat mapping in ecosystem-based management; ICES J. Mar. Sci. 66 2033-2042.

CONISMA-DisGAM 2002a Caratterizzazione morfologica di specchi d'acqua costieri ai fini di una revisione cartografica: Lago di Lesina; Report 73p.

CONISMA-DisGAM 2002b Caratterizzazione morfologica di specchi d'acqua costieri ai fini di una revisione cartografica: Lago di Varano; Report 70p.

Crisciani F 1994 L'idrodinamica della laguna di Lesina; In: La laguna di Lesina quali prospettive quali soluzioni?, Proceedings, Lesina, Italy, pp. 22-23.

Cucco A and Umgiesser G 2006 Modeling the Venice Lagoon residence time; Ecol. Model. 193 34-51.

De Pascalis F, Pérez-Ruzafa A, Gilabert J, Marcos C and Umgiesser G 2012 Climate change response of the Mar Menor coastal lagoon (Spain) using a hydrodynamic finite element model; Estuarine Coast. Shelf Sci. 114 118-129.

De Pippo T, Donadio C and Pennetta M 2001 Morphological evolution of Lesina Lagoon (southern Adriatic, Italy); Geogr. Fis. Din. Quat. 24 29-41.

D'Errico G, Giovannelli D, Montano C, Milanovic V, Ciani M and Manini E 2013 Bioremediation of high organic load lagoon sediments: Compost addition and priming effects; Chemosphere 91 99-104.

Duck R W and Figueiredo da Silva J 2012 Costal lagoons and their evolution: A hydromorphological perspective; Estuarine Coast. Shelf Sci. 110 2-14.

Ferrarin C and Umgiesser G 2005 Hydrodynamic modeling of a coastal lagoon: The cabras lagoon in Sardinia, Italy; Ecol. Model. 188 340-357.

Ferrarin C, Razinkovas A, Gulbinskas S, Umgiesser G and Bliudziute L 2008 Hydraulic regime-based zonation scheme of the Curonian Lagoon; Hydrobiologia $\mathbf{6 1 1}$ 133-146.

Ferrarin C, Umgiesser G, Bajo M, De Pascalis F, Ghezzo M, Bellafiore D, Mattassi G and Scroccaro I 2010 Hydraulic zonation of the Lagoons of Marano and Grado, Italy. A modelling approach; Estuarine Coast. Shelf Sci. $\mathbf{8 7}$ 561-572.

Ferrarin C, Bergamasco A, Umgiesser G and Cucco A 2013a Hydrodynamics and spatial zonation of the Capo Peloro coastal system (Sicily) through 3-D numerical modelling; J. Mar. Syst. 117-118 96-107.

Ferrarin C, Ghezzo M, Umgiesser G, Tagliapietra D, Camatti E, Zaggia L and Sarretta A 2013b Assessing hydrological effects of human interventions on coastal systems: Numerical application to the Venice Lagoon; Hydrol. Earth Syst. Sci. 17 1733-1748.

Ferrarin C, Zaggia L, Paschini E, Scirocco T, Lorenzetti G, Bajo M, Penna P, Francavilla M, D'Adamo R and Guerzoni S 2014 Hydrological regime and renewal capacity of the micro-tidal Lesina Lagoon, Italy; Estuaries and Coasts 37 79-93.

Flemming B W 2000 A revised textural classification of gravel-free muddy sediments on the basis of ternary diagrams; Cont. Shelf Res. 20 1125-1137.
Fortune S 1987 A sweepline algorithm for Voronoi diagrams; Algorithmica 2 153-174.

Frontalini F, Margaritelli G, Francescangeli F, Rettori R, Armynot Du Châtelet E and Coccioni R 2013 Benthic foraminiferal assemblages and biotopes in a coastal lake: The case study of lake Varano (southern italy); Acta Protozool. 52 147-160.

GRASS Development Team 2013 GRASS 6.4 Users Manual. Open Source Geospatial Foundation, USA. Electronic document: http://grass.osgeo.org/grass64/manuals/.

Isaaks E H and Srivastava R M 1989 Appl. Geostatistics; Oxford University Press, New York.

Kjerfve B 1986 Comparative oceanography of coastal lagoons; In: Estuarine Variability (ed.) Wolfe D A (New York: Academic Press), pp. 63-81.

Levin S A 2001 Encyclopedia of Biodiversity; Academic Press, San Diego, CA.

Lourido A, Moreira J and Troncoso J S 2010 Spatial distribution of benthic macrofauna in subtidal sediments of the Ría de Aldán (Galicia, northwest Spain); Sci. Mar. 74 705-715.

Lucieer V and Lucieer A 2009 Fuzzy clustering for sea floor classification; Mar. Geol. 264 230-241.

Malhadas M S, Neves R J, Leitão P C and Silva A 2010 Influence of tide and waves on water renewal in Óbidos Lagoon, Portugal; Ocean Dynam. 60 41-55.

Manini E, Breber P, D'Adamo R, Spagnoli F and Danovaro R 2002 Lesina Lagoon-Italy; In: Nutrient fluxes in transitional zones of the Italian coast (eds) Giordani G, Viaroli P, Swaney D P, Murray C N, Zaldívar J M and Marshall Crossland J I, LOICZ Reports and Studies No. 28, pp. 49-54.

Manini E, Fiordelmondo C, Gambi C, Pusceddu A and Danovaro R 2003 Benthic microbial loop functioning in coastal lagoons: A comparative approach; Oceanol. Acta 26 27-38.

Marzano C N, Liaci L, Fianchini A, Gravina F, Mercurio M and Corriero G 2003 Distribution, persistence, and change in the macrobenthos of the lagoon of Lesina (Apulia, southern Adriatic Sea); Oceanol. Acta 26 57-66.

Mitasova H and Mitas L 1993 Interpolation by regularized spline with tension: I. Theory and implementation; Math. Geol. 25 641-655.

Mitasova H, Mitas L, Brown W M, Gerdes D P, Kosinovsky I and Baker T 1995 Modelling spatially and temporally distributed phenomena: New methods and tools for GRASS GIS; Int. J. Geogr. Inf. Syst. 9 433-446.

Molinaroli E, Guerzoni S, Sarretta A, Cucco A and Umgiesser G 2007 Link between hydrology and sedimentology in the Lagoon of Venice, Italy; J. Mar. Syst. 68 303-317.

Molinaroli E, Guerzoni S, Sarretta A, Masiol M and Pistolato M 2009a Thirty-year changes (1970-2000) in bathymetry and sediment texture recorded in the lagoon of Venice sub-basins, Italy; Mar. Geol. 258 $115-125$

Molinaroli E, Guerzoni S, De Falco G, Sarretta A, Cucco A, Como S, Simeone S, Perilli A and Magni P 2009b Relationships between hydrodynamic parameters and grain size in two contrasting transitional environments: The Lagoons of Venice and Cabras, Italy; Sedim. Geol. 219 196-207.

Neteler M, Bowman M H, Landa M and Metz M 2012 GRASS GIS: A multi-purpose open source GIS; Environ. Modell. Softw. 31 124-130.

Oakley B A, Alvarez J D and Boothroyd J C 2012 Benthic geologic habitats of shallow estuarine environments: Greenwich Bay and Wickford Harbor, Narragansett Bay, Rhode Island, USA; J. Coastal Res. 28 760-773. 
Pérez-Ruzafa A, Mompean M C and Marcos C 2007a Hydrographic, geomorphologic and fish assemblage relationships in coastal lagoons; Hydrobiologia $\mathbf{5 7 7}$ 107125.

Pérez-Ruzafa A, Marcos C, Pérez-Ruzafa I M, Barcala E, Hegazi M I and Quispe J 2007b Detecting changes resulting from human pressure in a naturally quick-changing and heterogeneous environment: Spatial and temporal scales of variability in coastal lagoons; Estuarine Coast. Shelf Sci. 75 175-188.

Pérez-Ruzafa A, Marcos and Pérez-Ruzafa I M 2011 Mediterranean coastal lagoons in an ecosystem and aqautic resources management context; Phys. Chem. Earth 36 160-166.

QGIS Development Team 2013 QGIS Geographic Information System; Open Source Geospatial Foundation Project, http://qgis.osgeo.org.

Renzi M, Specchiulli A, Baroni D, Scirocco T, Cilenti L, Focardi S, Breber P and Focardi S 2012 Trace elements in sediments and bioaccumulation in European silver eels (Anguilla anguilla L.) from a Mediterranean lagoon (SE Italy); Intern. J. Environ. Anal. Chem. 92 676-697.

Ribbe J, Wolff J O, Staneva J and Gräwe U 2008 Assessing water renewal time scales for marine environments from three-dimensional modelling: A case study for Hervey Bay, Australia; Environ. Modell. Softw. 23 12171228.

Roselli L, Fabbrocini A, Manzo C and D'Adamo R 2009 Hydrological heterogeneity, nutrient dynamics and water quality of a non-tidal lentic ecosystem (Lesina Lagoon, Italy); Estuarine Coast. Shelf Sci. 84 539-552.

Roselli L, Cañedo-Argüelles M, Costa Goela P, Cristina S, Rieradevall M, D'Adamo R and Newton A 2013 Do physiography and hydrology determine the physico-chemical properties and trophic status of coastal lagoons? A comparative approach; Estuarine Coast. Shelf Sci. 117 29-36.

Shumchenia N and King J W 2010 Comparison of methods for integrating biological and physical data for marine habitat mapping and classification; Cont. Shelf Res. 30 1717-1729.

Spagnoli F, Specchiulli A, Scirocco T, Carapella G, Villani P, Casolino G, Schiavone P and Franchi M 2002 The
Lago di Varano: Hydrologic characteristics and sediment composition; Mar. Ecol. 23 384-394.

Specchiulli A, Focardi S, Renzi M, Scirocco T, Cilenti L, Breber P and Bastianoni S 2008 Environmental heterogeneity patterns and assessment of trophic levels in two Mediterranean lagoons: Orbetello and Varano, Italy; Sci. Total Environ. 402 285-298.

Specchiulli A, Renzi M, Scirocco T, Cilenti L, Florio M, Breber P, Focardi S and Bastianoni S 2010 Comparative study based on sediment characteristics and macrobenthic communities in two Italian lagoons; Environ. Monit. Assess. $160237-256$.

Stamou A I, Memos C and Spanoudaki K 2007 Estimating water renewal time in semi-enclosed coastal areas of complicated geometry using a hydrodynamic model; J. Coast. Res. SI50 282-286.

Stewart L K, Kostylev V E and Orpin A R 2009 Windowsbased software for optimising entropy-based groupings of textural data; Comput. Geosci. 35 1552-1556.

Stolt M, Bradley M, Turenne J, Payne M, Scherer E, Cicchetti G, Shumchenia E, Guarinello M, King J, Boothroyd J, Oakley B, Thornber C and August P 2011 Mapping shallow coastal ecosystems: A case study of a Rhode Island Lagoon; J. Coast. Res. 27 1-15.

Tagliapietra D and Volpi Ghirardini A 2006 Notes on coastal lagoon typology in the light of the EU Water Framework Directove: Italy as a case study; Aqautic Conserv: Mar. Freshw. Ecosyst. 16 457-467.

Tagliapietra D, Sigovini M and Magni P 2012 Saprobity: A unified view of benthic succession models for coastal lagoons; Hydrobiologia 686 15-28.

Umgiesser G, Melaku Canu D, Cucco A and Solidoro C 2004 A finite element model for the Venice Lagoon. Development, set up, calibration and validation; J. Marine Syst. 51 123-145.

Vignes F, Barbone E, Breber P, D'Adamo R, Roselli L, Ungaro N, Focardi S, Renzi M and Basset A 2009 Spatial and temporal description of the dystrophic crisis in Lesina lagoon during summer 2008; Transit. Waters Bull. $347-62$.

Woolfe K J and Michibayashi K 1995 Basic entropy grouping of laser-derived grain size data: An example from the Great Barrier Reef; Comput. Geosci. 21 447-462. 